\title{
RTM TEXT
}

Australasian Association of Writing

Programs

\section{Journal of writing and writing courses}

ISSN: 1327-9556 | https://www.textjournal.scholasticahq.com/

\section{Un-knowing expertise in the time of pandemic: Three teaching perspectives}

Bonny Cassidy, Linda Daley and Brigid Magner

To cite this article: Cassidy, B., Daley, L., \& Magner, B. (2021). Un-knowing expertise in the time of pandemic: Three teaching perspectives. TEXT: Journal of writing and writing courses, 25(2): 1-19. 


\title{
RMIT University
}

Bonny Cassidy, Linda Daley and Brigid Magner

Un-knowing expertise in the time of pandemic: Three teaching perspectives

\begin{abstract}
:
This article frames three individual perspectives on the experience of unsettling disciplinary and institutional subjectivities through teaching and learning practices in Creative Writing and Literary Studies. At the centre of this experience is a common engagement of teaching and learning with sovereign knowledges. More specifically, the accounts in the article are drawn from experiences in 2020, when the forces of extra-academic life - especially lockdown during COVID-19 in Victoria - intensified the objectives and the means of challenging the boundaries of settler colonial expertise. The authors find that collaborative and iterative sharing of teaching experiences and methods not only supported them during a time of acute change but also empowere them to take risks that challenge disciplinary authority. In seeking to un-learn their privilege together and with their students, the authors reflect here on a set of new pedagogical contexts and approaches that are perpetually in-process.
\end{abstract}

Biographical note:

Bonny Cassidy is Senior Lecturer in Creative Writing at RMIT University. Her third poetry collection, Chatelaine (Giramondo, 2017), was shortlisted for the 2018 Prime Minister's Literary Awards. Her essays on Australian poetics and culture have been widely published in Australia and internationally.

Linda Daley is Senior Lecturer in the School of Media and Communication at RMIT University where she has been teaching literary and communication studies for nearly two decades. She is the author of publications spanning literary, cultural and communication studies in local and international journals.

Brigid Magner is Senior Lecturer in Literary Studies at RMIT University. She has been living and working on Wurundjeri land since she migrated from Aotearoa in 1995. Her monograph Locating Australian Literary Memory was published in 2019.

Keywords: sovereignty, deep listening, embodiment, literary studies, creative writing 


\section{Un-knowing expertise in the time of pandemic: Three teaching perspectives}

We have been working together at RMIT University in the Creative Writing and Literary Studies program for at least five years. Over time, we have become aware of our shared interest in First Nations texts, authors, and knowledge systems. In 2017, the university announced its Reconciliation Action Plan and in 2019 rolled out the Bundyi Girri program; a national first in developing and supporting non-Indigenous staff in relation to sovereign knowledge systems. [1] This work prompted us to interrogate our own relationships with First Nations principles of storytelling in our teaching practices, and to realise that we had similar aspirations as teachers which led us into an ongoing collaboration.

In this article, we frame three individual perspectives on the experience of unsettling our disciplinary and institutional subjectivities through teaching and learning practices in Creative Writing and Literary Studies. At the centre of this experience is our common engagement of teaching and learning with sovereign knowledges. More specifically, our accounts of this engagement as teachers are drawn from experiences in 2020, when the forces of extra-academic life - especially lockdown during COVID-19 in Victoria - intensified the objectives and the means of challenging the boundaries of settler colonial expertise. We have found that our collaborative and iterative sharing of teaching experiences and methods not only supported us during a time of acute change, but has also empowered us to take risks that challenge our disciplinary authority. In seeking to unlearn our privilege together and with our students, we reflect here on a set of new pedagogical contexts and approaches that are perpetually in-process.

We draw from pedagogic thinkers for whom unsettling or unlearning occurs as a subjective transformation for either student or teacher (Biesta, 2016a, 2016b; Collis \& Crawford, 2018; Friere, 2018). Where Biesta (2016a, p. 3) calls for a pedagogy of risk as the essential element increasingly missing in education debates, we explore our concrete experiences of that risk as a transformation of our own mastery or privilege in different ways: as expert disciplinary knowers and as professionally skilled communicators of that knowledge. For Biesta, the creativity of risk in education seeks transformations that are not toward an institutional or disciplinary ideal, whether understood as the job-ready graduate or even the life-long learner (2016a, p. 140). Rather, it is the risk of moving away from known and predictable subject positions. Awareness of risk in the learning and teaching experience is a dynamic that occurs between teacher and student as much as within teacher or student. Concretely, risk can be felt as a micro-transformation between teacher and student ensuring an open and creative pedagogy that, while not a guarantee, may contribute to wider transformations essential to a socially just and democratic polity. The risk that we describe from working with First Nations' sovereign knowledge principles and protocols is that we are not only transforming what or how we teach, but also the relations through which teaching and learning occur.

Barkindji man Paul Collis and Pākehā Jen Crawford's two-part manifesto (Collis \& Crawford, 2017, 2018) for the creative writing classroom outlines six principles for Creative Writing and Literary Studies pedagogy of First Nations stories. One of these principles expresses the Lakota First People's practice of "fierce listening" to stories that makes the role of the listener one of responsibility, not only response (Collis \& Crawford, 2017). Transposed to the writing classroom, Collis and Crawford view this mode of encounter as a "sensory openness" that is essential to discussions of writing and implicating the listener to the story 
within an emplaced and embodied encounter (Collis \& Crawford, 2018). Each of these thinkers, one of risk, the others of responsibility, adopts pedagogies that see classrooms as sites of openness and transformation both within and beyond their institutional settings.

\section{Bonny: Embodying the unknown}

"We do culture together: culture becomes in collaboration, conscious or unconscious". This "grounding" drawn from Collis and Crawford's approach to "Aboriginal and Torres Strait Islander story in the Australian creative writing classroom" is a potent and sometimes provocative intervention upon Creative Writing pedagogy (Collis \& Crawford, 2017). It challenges the foundational assumption of what Paulo Friere called the "banking" method of education (Friere, 2018, p. 72). In that method, the teacher-expert transfers knowledge to the student like a deposit into an account. The ideal is based upon a hierarchy of knowledge and an uncritical reproduction of information that ensures the disciplinary and institutional status quo of the discipline.

Creative Writing works from a slightly different pedagogical tradition based in industrial methods of mentorship and practitioner experience as academic authority (see Donnelly 2012). In this way, there is a little more room for a dialogic mode of learning between teacher and student, and for reflection upon learning as well as content, than in traditional humanities. Nevertheless, the discipline rewards the expertise of the teacher as master, the virtuosic trajectory of the student (through the appreciation of craft), and particularly the refinement of the work to an externally demonstrable standard (publication or production). In other words, risk in undergraduate Creative Writing teaching is commonly defined by the student's lack of knowledge; the trials of their apprenticeship (see Cole 2007).

Such measures of success for both teacher and learner - indicated through assessment criteria and enrolment structures, academic contracts, awards and promotion - are equally revealed by what they exclude. Namely: a teacher who risks a standard of work that is no better than the student; a student who does not specialise in one writing form; and the mutual failure to show a resolved creative artefact as the ultimate outcome of their interaction. There are many reasons why these situations might arise for either teacher or student, but the one I want to focus on is the troubling of the discipline's assumed purpose and definition as a dominant settler colonial discourse. What sorts of risks are posed by this troubling; and what can they tell us about responsibility and implication?

Setting Aboriginal and Torres Strait Islander story at the centre of their pedagogical collaboration, Collis and Crawford illuminate ways of learning that unsettle the knowledge hierarchy of institutional Creative Writing in Australia (see Cassidy 2020). My particular interest in their principle that "we do culture together" has manifested as three key experiences in my recent teaching. As with my co-authors, integrating a relationship with sovereign story and knowledges is the catalyst of these experiences; but the myriad impacts of social isolation during the COVID-19 pandemic of 2020 have amplified the significance of provoking the boundaries of our disciplines and institutional subjectivities.

A multi-generation settler of Irish and German heritage, I live on Dja Dja Wurrung lands in central Victoria. In 2020 I designed and delivered a new course for undergraduate Creative 
Writing majors, "Writing with Sovereign Spaces". [2] Centering the course on the class group's shared relationship with Kulin Country on campus and the Welcome from Kulin Elders at RMIT, my intention was to work alongside my students in learning to find the words to recognise and acknowledge sovereign locality; and to practise "fierce listening" to Kulin place and story. While I might have been a few steps further than my students along the road of reflexive thinking, I was, am not and never can be expert in the knowledge at the centre of the course. This raised two risks for me, which I anticipated in designing the course but couldn't fully appreciate until I was delivering it: I could not primarily be a knower to my student's learner; and, therefore, the learning could only work if it were collaborative, active and iterative.

The three key experiences I want to highlight concern the de-privileging of literary formalism in favour of listening and expressive authenticity; sharing intimacy and power in the classroom, at the cost of professional and cultural authority; and working with circular, gradual and unfinished creative outcomes.

My course was explicitly offered to students of all cultural backgrounds. The cohort in the 2020 iteration were (self-identifying) non-Indigenous from a range of cultural and linguistic heritages. The course was designed as a studio: an intensive delivery of five, face-to-face contact hours per week, focused on practice-based learning. Due to campus closure under the pandemic, however, face-to-face classes were replaced by fully online delivery.

This unexpected pivot only served to heighten the experiences to which I've alluded. At the core of the course materials, the required "readings" of Kulin authorship were not readings at all. At first, I chose audio and visual media as well as electronic text because I couldn't easily retrieve, scan or upload print off-campus. However, I soon realised that this multimedia storytelling was finding me: Koori Heritage Trust, ABC Radio National's AWAYE! program, The Red Room Company, Culture Victoria web archive and NITV are repositories of diverse, contemporary cultural production and revival including Kulin. This range of representation demonstrated to our group that "culture becomes", it is never static, and that much Kulin storytelling is situated in collective productions rather than sole authorship.

This combined with the mix of available media - documentary, reportage, poetic - invited us to set aside reductive formal categories of the discipline such as short stories or lyrics. Since we were not framing Kulin story as exemplary of anything other than itself, we instead paid attention to these media as embodiments of sovereign knowledges. Guiding this were the words of Boon Wurrung Elder, N'Arweet Carolyn Briggs in her Foreword to ACCA's Sovereignty exhibition catalogue, that "Dance, story, images and song - all have a role to play in knowledge transmission" (Briggs, 2017, p. 4).

Privileging multimedia in a Creative Writing studio de-privileged my expertise as a practitioner in Anglophone, canonical genres of writing. It also questioned some of the formal specialisations in which previous courses had trained the students, and required us to begin learning other, less predictable ways to engage.

One of these ways was an interpretation of "fierce listening". Our class drew from a local source: Gulpa gnawal or "deep listening” as it is described by Yorta Yorta/Dja Dja Wurrung musician, Dr Lou Bennett (ABC Radio National, 2012). Learning online assisted this practice 
in class because we were able to turn off our cameras. Our faces were an intuitive optical focus but also a distraction from other ways of paying attention. At first, we took short periods of time away from the screen, to practice at home and then return to the online group to share what we had noticed. Many of the students lived in metro Melbourne, under advanced lockdown; they were not permitted to walk more than a few blocks from home each day. Practising Gulpa gnawal allowed them to find opportunities for noticing in their all-toofamiliar home environments. "I live on an intersection and I heard that the magpies have timed their carolling to happen while the cars are halted at the lights", mentioned one student. "I realised there was no silent moment", said another, "there was always a sound shaping the air". In these conversations my job was to offer little response, only to encourage noticing and sharing of the experience, including my own participation.

We then tried practicing this as an audience to the human voice. First, we listened to an interview and statement by Bunurong/Yuin author Bruce Pascoe about his poem "Kuller Kullup" (Red Room Company, 2017). We talked about poetics not as stanzas or lines but as pauses and emphases, tones and the way recorded silence is also full, and attended to the cadence and tone of Pascoe's delivery, including pronunciation of language words. I found that the students consistently linked the history and experience in Pascoe's interview with the affects of the poem.

This activity was a slow way of learning. It was also a way of learning about writing as contingent upon history, experience and language. We were slowly learning to listen to a sovereign voice, and to be implicated by its sovereign status, rather than colonise it as "a literary object for close reading without context or reflection on the role of the reader" (Archer-Lean \& Phillips, 2018, p. 27). Tony Birch describes how sovereignty "is an embodied experience, at times literally transcribed on and within the body" (2017, p. 21). Practising deep listening alongside this description helped our group to begin understanding and witnessing sovereignty in terms of lived practices, rather than a status described by an English word within an imperial legal framework.

Our attunement to witnessing sovereign practices also attuned us better to one another. At times I felt discomfort in inviting the students to work outside their burgeoning skills and confidence within a certain system of education. They were at times incredulous, angry and frustrated about undoing their conventional sense of teleological achievement. Speaking from hindsight, a student described this disappointment: "I couldn't understand where the content was taking me, and I was still clutching to my preconceived notions of what we should be doing" (Anonymous in Cassidy 2020, Reflexive learning survey). A couple of students never really recovered from this provocation. They soon stopped attending classes and struggled to submit assessments once our discussions deepened in reflexivity. My suspicion is that, for as long as academic structures are centred on settler colonial methods of knowing and learning, there will always be this minority of resistance. The majority of the group gradually realised that a responsiveness to sovereign knowledges might mean very little in the way of recognisable creative writing or very little within the provided duration of a semester. We seemed to be working backwards: the production of a creative artefact was replaced by an interrogation of purpose and responsibility as participants in an oppressive knowledge system. 
The only way I could navigate this with them was to lean into my own forfeiting status as a knowledge leader. Subconsciously, this took place through the interpersonal modes of online learning. Without the neutral institutional backdrop of a generic room, in which all I bring of myself is what I wear or carry, my class was present in my home and I in theirs. This was often difficult for me: my autistic husband's income was lost due to lockdown, which forced us to move house once the rent debt became insupportable. The death of a family member behind closed state borders sent crooked waves of grief through our lives. Moving off-grid meant my workspace was provisional, my internet connection and power supply were patchy, sometimes I hadn't showered if the tank pump had cut out. I explained much more of this to the class than I ever would have in an institutional setting, as my typical sense of professional formality was steadily eroded. Partly this was out of necessity - when I was logging on from an echoing room emptied of furniture or when my dogs were barking at a snake - and partly because the students constantly offered uninvited glimpses into their own lives at home. As Brigid and Linda detail below: beds, meals, renovations, relatives, partners, pets, yawns and gulps all tumbled through the microphones and cameras.

One student remarked in an assessed reflection task that "the possibility of having a teacher to not only teach but also learn with, to grow with ... is especially important considering these unprecedented times" (Anonymous in Cassidy 2020, Reflexive learning survey). The erosion of my authoritative appearance and the students' attentive role-playing was an unplanned material corollary to the cultural and institutional provocations I had deliberately invited into our syllabus. It seemed that together we were indeed constructing a new way to be in relation, a culture "conscious and unconscious" that was appropriate to the needs of our learning. While those needs were primarily defined by an alternative knowledge system, they were heightened by the conditions of mass social arrest generated by the pandemic and, shortly before lockdown, the local movement of Black Lives Matter.

The more we expected of the group to collaborate on our learning, however, the more independent resilience was required of each participant. We shared a blog platform, which offered a diaristic space to capture the excesses of learning - research ideas, questions, drafts or revisions, moods, changes of mind and many seemingly dead-ends. Intending to emphasise the open-endedness of our purpose, I participated in the blog, testing out prompts I had shared and risking creative attempts to demonstrate an iterative process. My participation had a greater effect on my pedagogical ego than I'd expected, as I observed a further flattening of the creative mentor-apprentice hierarchy. I spent much time honestly wondering what students were making of the half-baked drafts I had posted and surfing their numerous innovative, curious posts that were humbling in maturity and commitment. As one student wrote in a survey I took of the group: "I think Bonny would have learned how diverse the responses from non-indigenous [sic] people about sovereign spaces are. How we all struggled with our own discomfort in different ways and how we expressed this through writing very differently" (Anonymous in Cassidy 2020, Reflexive learning survey).

The blog created a horizontal learning structure, floating free of contact hours and my class plans and, as it happened, receptive to the way clock hours melted during lockdown. Students could $\log$ on at 1 am and post a reflection or look at their friend's latest draft. I was able to oversee individual work and offer more personalised consultation. Moreover, the blog medium encouraged students to prod at the limits of their own knowledge about story. They found that they had to sharpen decisions about what images "say" and how to reference 
knowledge sources appropriately in an online format. Some students took the blog itself as a creative affordance, composing with scrolling images, parallel columns and video. This was more than creative play in its own right: these emerging writers sought hybrid forms, assemblage and graphic work that prioritised urgency and care over resolution and polish.

That my co-authors and I share a number of students across our courses also became evident as another form of decentred teaching authority. One student, in a blog post for my course, highlighted their enjoyment of "interactive learning between myself and my teachers, even though it was outside of the ... classroom" (Anonymous in Cassidy 2020, Reflexive learning survey). When I first read this, I thought the plural was a typo; re-reading it, though, I grasped that the student perceived themselves as working between courses, actively making critical connections across disciplines and texts from various sources. They may also have been indicating that the cultural authority of Kulin and other First Nations media had expanded their cohort of teachers. In situating their learning "outside" the classroom, this student not only realised themselves as a collaborative agent rather than an institutional subject; they also taught me that education takes place somewhere other than either the virtual or material classroom - in the learner's body, with the land around it. [3]

\section{Brigid: Leaning in to place}

I am a fifth generation Pākehā woman from Aotearoa (New Zealand) with Irish and English heritage. Although I came from a country with a similar colonial history of invasion and conquest, the implications of living on stolen land in Australia took me a long time to process. I wanted to know more but I was not sure how to come by this information and who to discuss it with.

When I began working as a lecturer at RMIT in 2007, there was little formalised discussion of Reconciliation. I was reluctant to pretend to have any expertise in relation to First Nations knowledges. I harboured a desire to include First Nations perspectives in my teaching, but guest lecturers tended to perform this labour because I felt under-equipped to lead informed discussion. I have come to understand that First Nations voices should ideally be centred rather than confined to a particular week of a course and that, in doing so, I do not need to speak for them.

I want to talk about two courses that I have been coordinating and teaching for over five years. One reflects my tentative work towards decentering my knowledge when teaching Australian Literature; the other shows me how very recent experiences of online teaching have emboldened myself and my students to ground our work in co-naming.

The first of my two courses, Contemporary Australian Writing, originally opened for creative writing students only, but it is now framed within Literary Studies. The course aims to provide an overview of new Australian writing and to develop the critical and analytical abilities of students in this context. It begins with a consideration of the long history of First Nations storytelling - and the recognition, derived from Collis and Crawford's grounding, that: "Indigenous story is literary history, literary history is creative power" (Collis \& Crawford, 2018). 
A question which recurs throughout the course is: "how do we define an Australian writer?" By reading and discussing the work of authors who are not generally seen as Australian authors, such as the former asylum seeker Behrouz Boochani, students begin to see that this can be a capacious and inclusive category. First Nations authors problematise this classification too, given that they have inhabited the continent for millennia, before it was called Australia by settlers. Following the much-debated Macquarie PEN Anthology of Australian Literature (2010), this course offers a broad definition of what "writing" is, to include oral storytelling, letter-writing, speeches and other so-called ephemeral works that demonstrate First Nations literary history.

The first assignment focuses students' reflection on the "creative power" of voice. It asks students to respond to Tamika Worrell's autobiographical essay "The Aboriginal Equation" from the anthology Growing Up Aboriginal in Australia. Worrell begins with a list of statements and questions that are directed at her:

"What percent Aboriginal are you?"

"You don't look like an Aborigine."

"You've done really well for an Aboriginal."

"You're not like those other ones - you're one of the good ones."

"You wouldn't have had it hard growing up."

"I'm darker than you are."

"Are you really Aboriginal?"

"So do you get all the benefits?"

"All Aborigines are angry."

"Get over it, it happened two hundred years ago. No one alive today was there."

"I'm not racist, I have an Aboriginal friend." (Worrell, 2018, p. 220)

I chose this piece because it is written by a young person who is relatable and direct. I felt that students might recognise some of the opening phrases from their life experience. In fact, I was surprised by the number of students who had made similar comments or asked the same questions of First Nations classmates at school, without realising they could be hurtful. This assignment made many people feel uncomfortable because it required them to confront their conditioning and think about the effects of commonly heard perspectives.

This assignment was designed after I read Clare Land's Decolonising Solidarity (2015), which made me think deeply about my identity as a non-Indigenous person and my unwilling complicity with colonial structures. I wondered how I could do something from my position as a teacher to confront my own white privilege and encourage non-Indigenous students to interrogate their own social conditioning in the context of language. While earlier iterations of the course included more traditional Literary Studies tasks that did not involve such selfinterrogation, I drew on the Creative Writing origins of the course to encourage this approach.

In 2018 I decided to implicate the class further in the reading of Worrell's essay. I asked students to read it aloud in class with each person reading a line each until it was finished. In this way, we gave space and time to listening to Worrell's story through the voices of various students. In so doing, we engaged in a kind of listening which is advocated by Ambelin Kwaymullina in Living On Stolen Land: 


\author{
Listening \\ means learning to hear \\ the noise of settler-colonialism \\ inside your head \\ and all around you \\ so you can hear past it \\ to understand our voices \\ on our own terms (Kwaymullina, 2019, pp. 55-56)
}

Non-Indigenous students, who are always the majority of the course enrolments, often become more aware of the "noise of settler-colonialism" inside their heads when voicing Worrell's text. Some students have suggested in their reflections that Worrell's piece triggers a range of feelings including shame, defensiveness and sadness. As Bob Pease argues, "generating discomfort among members of dominant groups can function to shift people out of their complacency and encourage a confrontation with complicity or privilege" (Pease 2012 in Land, 2015, p. 242).

As they articulate critical self-reflection for the assignment, using Worrell's text as a starting point, my students are asked to consider the workings of history and power in their own lives. The wording of the assignment originally implied that students should disclose any examples of prejudice that they had themselves experienced, but I removed this in 2019 as I felt it might be too intrusive and triggering for some students of minority identities. Others, however, felt like they shouldn't have to interrogate their white identity in a learning reflection - one non-Indigenous student claimed that this was an example of prejudice against people like him.

I am now motivated to find ways of addressing these responses in class. I wonder if my students could feel comfortable expressing ideas and beliefs that are not shared by me. Was writing the only way that some students felt they could express their discomfort or deflection? When is this a better outlet than speech, which can create a culturally unsafe environment for others? These reflections prompt me to think about how I could host more open conversations on these uncomfortable topics as part of the coursework, to include differing views while also guiding an understanding of why the course is invested in First Nations" "creative power".

The need to pivot to online teaching very suddenly in the first semester of 2020 meant that there was little time to prepare my course for online delivery. I delivered my classes from an old armchair in my bedroom because I didn't have a desk available. The computer was resting on top of a large book balanced on my lap, which meant that the camera moved every time I shifted in the seat. This felt precarious but also fairly intimate, in a way that was uncomfortable for me at first but partly overridden by the fact that students were also struggling with the shortcomings of their home learning environments. As Bonny has observed, it had the effect of "eroding" my professional demeanour to some extent, which meant that students said things that they may not have otherwise. The chat function encouraged students to express themselves in short bursts throughout the class. 
By the second semester, I had set up my workstation in a more ergonomic way, as the armchair teaching played havoc with my lower back. This time, I felt less afraid of things going wrong, having already dealt with moments of internet disruption and the difficulties of managing breakout groups. I found myself preparing materials very carefully beforehand in case exercises didn't work but I found that people were much more connected, seemingly pleased to be doing something engaging while stuck at home. There was a feeling of solidarity that I had not encountered in quite this way before. This sense of closeness however illusory - was achieved without two-way visual connection a lot of the time. Perhaps it's not always necessary to be looking at each other's faces in order to learn?

In this context, listening carefully became crucial to creating and sustaining rapport. The established etiquette for online classes with most people on mute could be difficult for me at times, given that it cancelled out the sounds that you would normally hear in class situations - sighing, gasping, noises of assent or disagreement, along with laughter. When students were working in small groups, I encouraged them to keep their mics and cameras on to make them feel like they were actually with people, however physically distanced.

The course, Reading Space and Place, is an undergraduate Literary Studies course that looks at these concepts of locality in both fiction and nonfiction from all over the world. Its grounding, however, is firmly in Australia. I have become increasingly critical of colonial mapping and naming processes in Australia, a practice shared with other colonised countries, and so I have invited students to rethink the ways in which they articulate the places they inhabit.

We look specifically at Melbourne (Naarm) and the various ways it has been represented in maps before and after colonial settlement. We consider hand drawn maps of Naarm by figures such as Billibellary of the Wurundjeri-willam people, who is from my own neighbourhood. I ask students to answer Gary Foley's question: "What do you know about what happened to the people who lived on the place you live now?" (qtd in Land 2011, p. 52) or "What happened to the local mob?" (qtd in Land 2015, p. 179) Often they do not know the names of the local places and peoples, but they become more curious about this as the semester progresses and start to notice council signage, naming of streets or special sites such as wetlands. Some even begin to imagine through research what their neighbourhood was like before colonisation, as one student did after reading Bruce Pascoe's Dark Emu (2014).

Under lockdown, Reading Space and Place offered the opportunity for exploration of students' neighbourhoods during hour-long walks. In the first class I asked people to name the country they were speaking from. I talked about my own daily walks and the discoveries I made, in order to generate conversation about their own suburbs. I told them of my realisation that the Assistant Protector of the Aborigines, William Thomas, lived near my house in a park now known as Bush Reserve. Thomas' homestead, named Strangway Farm, was a site of cross-cultural exchange for Kulin and non-Indigenous people. Large numbers of Kulin peoples sometimes turned up and camped around the house, including William Barak and Billibellary. Thomas' wife Susannah would cook meat and cabbage and assist the sick. Because it is now a playground, Bush Reserve is popular with the public, but many locals don't know its history. This anecdote prompted students to tell me what they had discovered about their own places. One student said that she found a sign near her house with Indigenous 
names for plants and animals from the area - she was amazed that she had never stopped to read it until walks became the highlight of each day.

Later, some of these observations were expanded upon for a psychogeography assignment, to be conducted within five kilometres of home due to restrictions. One student produced a piece of work which included observations about the island known as Deen Mar by the Gunditjmara people. She noted that she was never taught much about local First Nations history but had always been interested in finding out more. It was coincidental that she was sitting on the beach reading Dark Emu when she looked across at Deen Maar and realised that she had to write about it. In the conclusion to her psychogeography she observes:

Understanding ... the weight of importance that aboriginal people put on the land has made me think about all the wonders of the Victorian landscape and what aboriginal stories they hold [sic]. The way in which I look at plants, at coastlines, at stars and bugs has a whole new level of meaning when you look at it through a different lens. With this lens comes a new degree of appreciation for the landscape which I call home, and that so many generations before me have called theirs.

The "calling" of places resulted in a number of students who sought to co-name familiar localities in their assignments, partly using recent research into magistrate A.W. Howitt's notebooks. Writing about the restoration of First Nations names for the Grampians-Gariwerd in regional Victoria, Tony Birch argues that to name spaces is to "name histories", and also to create them:

The process is accepted as natural, representing a 'given', that this country belongs to and is a white Australia. But this sense of security evaporates when the hidden history of colonial domination and indigenous subordination is challenged by an attempt to alter the names of spaces (Birch, 1992).

Finding original place names, and thereby tacitly acknowledging First Nations sovereignty, required an effort which some students were not yet prepared to make. It requires an adjustment to a worldview which "naturalises" the superimposition of European place names during the process of colonisation. As a teacher, I have always hesitated to be overly prescriptive about exactly how students should approach their assignments. By suggesting that they acknowledge First Nations custodianship, I feared that I might be forcing certain conclusions on students, rather than letting them work things out for themselves. Yet, this prompt - to consider names - was a powerful dimension of the exercise for those who chose to take it up.

I plan to set a First Nations-authored text located in Melbourne for future iterations. This would almost certainly increase the students' level of engagement with the local Country. Nevertheless, students have shown an interest in First Nations histories of Melbourne even when reading the work of non-Indigenous writers such as Jennifer Down. This note was added to the caption of one of the visual analyses submitted to me by a non-Indigenous student:

This story elicited a strong sense of connection that I hardly ever feel with characters and places, as it's not often that I read about places that are so familiar, local, and 
similar to my own life. Feeling this sense of familiarity also made me wonder about different perspectives in history, in particular what the mapping of Melbourne would have looked like before colonisation. It is interesting to think about the areas I have visited and how they once would have looked when the traditional custodians of the land - the Bunurong Boon Wurrung and Wurundjeri Woi Wurrung People - were mapping Naarm.

In class, since students needed to unmute themselves to talk, the discussions were possibly less spontaneous than they might have been otherwise but verbal contributions were more carefully considered. Anything more casual or reactive tended to be put into the chat running alongside. I saw the two options (verbal and textual) as enriching one another, allowing me to connect with people who might normally stay silent and underscoring our work of connecting language with space. With the new knowledge students have gathered, they may be more able to look beneath Eurocentric names to the living country beneath.

\section{Linda: Listening to risk}

Collis and Crawford provide a model of knowing and learning based on six groundings of First Nations' traditions, perspectives and practices. One of these groundings: "Story transmits narrative responsibility. Narrative responsibility requires fierce listening" is described as a responsibility learned through a classroom-based writing assignment where each student is partnered with another as a listener to a story that they have a responsibility to narrate. Collis and Crawford claim that the writing activity establishes a responsibility "charged by an alertness to their listening role" where "the energy between [speaking and listening] partners is visibly reciprocal" (Collis \& Crawford, 2018). Fierce listening, say the authors, is also a way of ensuring that "story" is understood as "a living body of thought, experience, feeling and practice" rather than the transmission of narrative or the transcription of a narrative to a written artefact, as if these were merely a relay of representational content (Collis \& Crawford, 2018).

The "fierce listening" Collis and Crawford describe for the Creative Writing classroom has a close affinity with the "deep listening" concept of Gulpa gnawal that Bonny describes, and also with Dadirri as this concept is named by the Ngangikurungkurr people of the Daly River region of the Northern Territory (Unggunmerr-Baumann 2002). Like Gulpa gnawal, Dadirri requires silence and stillness for a multi-sensorial attunement to a concrete situation or a particular environment for understanding. Viewed as a "spiritual gift", Ungunmerr-Baumann suggests it is "perhaps the greatest gift to fellow Australians" from First Nations peoples (Ungunmerr-Baumann, 2002). Dadirri has cultural value in diverse situations and is adopted as a method for addressing chronic and/or painful issues within communities or between communities and government agencies for program and policy development (see Waller 2018). Whether as "fierce listening" or "deep listening," these concepts explicitly acknowledge the singularities and specificities of embodiment and emplacement of the listening subject that are gaining interest in broader education contexts (see HaroutunianGordon \& Laverty, 2011).

As Bonny and Brigid have described, these modes of listening transpose to the higher education Creative Writing and Literary Studies classroom as a type of apprenticeship for 
non-Indigenous readers and writers into the embodied and emplaced dimensions of listening to stories authored by First Nations writers. My heritage is also non-Indigenous, and my disciplinary expertise is in European thought and textual traditions. My professional development with First Nations writing and knowledge systems has been a slow process characterised by the fear of risking false steps whether in my writing or my teaching. Regarding teaching, that risk came from two flanks: hearing the outspoken, negative student reactions (expressed to me as my "white guilt" or "this writer really has bad grammar") and fearing misrepresentation or assimilation within an overwhelmingly Anglo-European disciplinary framework. One of the courses I teach, Literature's Ethics, aims to explicitly address these fears through its First Nations reading list. The list frames our reading aloud and collectively from Alexis Wright's novel, Carpentaria (2006).

While Brigid's teaching continued in 2020 to discuss First Nations authored texts, my teaching this year did not allow that usual focus. However, what was surprising to me was the way in which the necessity of fierce or deep listening provoked by the conditions of homebased teaching and learning would be transformative of my teaching practice. The nature of this workplace pivot being as rapid and profound as it was forced and enabled me to realise the notion of listening practices as (trans)formative of roles and relations, and not simply as an important communicative practice.

Narrating the Self is a literary studies course taken by creative writing students as well as students in a variety of media and communication programs. It examines closely attuned modes of reading texts expressing a (trans)formative relation by the writer about their reading and writing habits within a network of other familial, institutional and mediated relations. The course explores the idea of reading, writing and listening practices as "technologies of the self" that are both formative (or productive) and regulative (or restrictive) of the self these practices produce (see Foucault 1997). Foucault's "technologies of the self" emerges from his analyses of classical writings examining "writing [that] transforms the thing seen or heard "into tissue and blood" ... [i]t becomes a principle of rational action in the writer himself" (Foucault, 1997, p. 213). His claim is that writing and reading goes beyond knowing something by, for example, the learner; it is formative of the learner. The writing and reading practices Foucault analysed are premised on an "ethic of listening" that could also be described as "deep" or "fierce," and which he tells us is "the first move in ascesis and the subjectivation of true discourse ... [that] forms the matrix for ethos" (Foucault, 2001, p. 334). Listening, for Foucault, is the first step to (trans)forming oneself and this necessarily occurs with others and is (trans)formative of those relations; listening is the basis of an ethos.

What do we need to know about listening as a set of techniques or technologies that could foreground the (trans)formation of these relations? How might we think of First Nations principles and practices as modelling technologies of listening for the (trans)formation of pedagogical relations? As Justine Lloyd (2009) claims, to revalue conventionally subordinated practices such as listening does not in itself guarantee what will be (trans)formed if there is not also an understanding of how power relations inflect the socialities in which speaking and listening occur. Following Foucault, power relations can be seen as formed and transformed by forces or materialities that may not only be restrictive, but also as enabling. These materialities include the modes of embodiment and emplacement that each of us have drawn attention to in relation to teaching and learning. They also include and this year of the pandemic brought these to the fore - the computational materialities such 
as hardware, software, and bandwidth, for example. Computational materialities include not only the digital divide of who has (or not) access to these material resources. They also include the affordances of the seemingly immaterial nature of computational modes of learning.

Under the constraints of lockdown there was a fragility and intimacy to the entire twelveweek semester. Hour upon hour, week upon week, we spoke to each other slowly and carefully as if through a crackly telephone line, eventually coming to recognise voices before the mic symbol identified the speaker from the participant list, which is viewable when the chat line is not. Before that point, we learned to feel our way with each other as the newly blind do in navigating once familiar footpaths. We eventually created something like what sound theorists would call an acousmatic relation while also making audible the conditions under which this classroom relationality was being formed (see Kane 2014). My term, acousmatic listening, describes the experience where the source of the sound is invisible or "veiled" from what can be seen, enabling the sound to move from an event to an object, the effect of which is to heighten the listening. For example, the sounds of words spoken "in the classroom" intermingled with household voices, footsteps on floorboards, doors opening and closing, birdsong, doorbells, clock chimes, car screeches, etcetera. Not only was the source of the sound invisible and unlocatable, sometimes it was unclear what the sound was such that it could be recognised at all.

Isolating the sounds of the spoken words from these intermingled background sounds, in addition to identifying the speaker of the words amid the more than twenty class members, required a high degree of attention from me. Over the course of several weeks a pattern emerged: I came to realise who would be the first to speak; who would sustain the discussion; and who would remain a silent listener. Acousmatic listening long predates audio technologies (Kane, 2014, p. 5). The affordances of course management systems like Canvas, with their functionality of Collaborate Ultra that allows students to turn their cameras on or off and to disappear behind the "Pythagorean veil," leaves it undetermined by the teacher whether they do so for personal or technological reasons. [4] Behind the turned-off camera (and routinely the turned-off mic) the soundscape of the classroom discussions upon which the tutorial activity focused were invisible but their material possibility became newly audible.

Foucault describes listening and the comportment of the listener - not only silent but physically immobilised - as the first step of self-discipline of the ancient figure seeking mastery of the logos. As the teacher I would always have my mic on and, most of the time, also my camera, until faltering connection issues forced me to turn it off to preserve bandwidth and therefore preserve the platform for hearing. On the whole, though, I was visible to students, but they were mostly not visible to me or to each other. A few students had avatars of their online identity that would appear on my screen in their stead (usually a cartoon hero, a fantasy figure, or some non-identifying image). In my hastily set up home office, I would sit at the desk straining to hear what I could not see, with my spine at a nearfixed forty-five-degree angle toward the laptop microphone, just as Brigid leaned towards her screen from her bedroom armchair. Tutorials came to be an encounter of listening closely for the microsounds of an unknown, invisible voice amid unknown multiple voices, along with 
the sub-audible sound particles of the fibre-optic cables upon which hearing those voices depends. Sound particles of voices and connections would come and go within the time of a tutorial, connecting and reconnecting as visible evidence on screen of the fragility of the digital and, I would add, the social connection. The accretion of these sound particles came to constitute a rhythm that I became aware of beneath the larger units of sounds, those rare occasions of whole exchanges across the classroom, and beneath larger units of meaning like the workbook assignments, just like the latter might occur in a physical room in a regular semester.

One voice in particular seemed to be not only hesitating in what or how she could say what she wanted to contribute, but occasionally hesitant whether she could speak at all. Her voice, which we came to rely on during the twelve weeks, often sounded like it would break, as if perhaps neurologically more than technologically - the connection between thought and statement would falter. Sound particles or micro-sounds constituted these gaps in communication: her breathing, her sighs, the stretched-out phonemes, the subverbal noises of the "live", unrehearsed voice aware that it is being heard by unknown, unseen, multiple others. The online medium accentuated her vocal fragility but, at the same time, the "darkness" of the room gave its vulnerability greater purchase. In a physical classroom, her slowness of expression, her capacity to throw her thoughts for others to catch, would have been difficult. Instead, in the dark, near-anonymity of the online classroom, a collective patience was rewarded: a slowly delivered, highly considered thought became an inspiring one; a slow but confessional anecdote illustrated exactly a point in the reading. Love hearts and thumbs-up pinged through the chat line in response. It wasn't just me listening hard, willing her to make that leap from one word to the next.

After more than eight weeks of lockdown, and still a quarter of the semester to go, I shifted gears at the start of each tutorial, asking students to share a "little story" on mic at a time after the Acknowledgement of Country I would make. It was the stage of the lockdown-semester when it felt like "nothing" was happening in the unending, featureless grey of winter, the same rising numbers of cases and aged-care deaths led the nightly news, and the same unending sense of the density and weight of the present was at its heaviest in the classroom. With some coaxing, stories emerged. We found that things were happening, and we found that making a "little story" of our day or week mattered more than the embarrassment or discomfort in not having "interesting" or "exciting" things to tell. Students began to describe a visitor to their home; the excitement of a parcel or letter delivery; some described the walks they took; a bird or animal that crossed their path; a book they had read that wasn't attached to an assessment; among others. The chat line fired up and little tributaries of conversation flowed from "behind the veil," but still "in the room". Something communal rather than individual was formed by speaking and listening to these stories.

\section{Conclusion}

Without a staff kitchen or an office stairwell in which to find ourselves exchanging anecdotes of the year that had passed, we came together virtually in late 2020 with the purpose of sharing notes on what had been physically and emotionally siloed teaching experiences. We had explored the synergy between our pedagogical interests and courses in a team-teaching award with a fourth colleague earlier in the year, but this application hadn't provided us the 
opportunity we needed to speak about the "art" of teaching (Biermann and Townsend-Cross, 2008, p. 148); nor had it encompassed the full extent of the year's pandemic impacts.

In the context of our institutional power as non-Indigenous academics, we understand risk as power-sharing with students as co-learners and with sovereign knowledge as transmitted through story. In the context of the pandemic during 2020, risk was inevitable in our teaching; discomfort with isolation and technical flow pushed us to more consciously recognise risk as a pedagogical tool. One of the common techniques we noticed when bringing together our experiences is the use of questioning as a teaching and learning strategy that both declares and invites un-knowing. It's appropriate that our sharing of attempts to decentre our expertise from our courses and to engage students in acts of acknowledging sovereign creative power leaves us with more questions for ourselves.

In this sense, we are now students of Friere's critical pedagogy who are engaged in the act of "problem-posing" as learning. In doing so, we seek to work together to articulate what it is that we want to learn, why and how we will continue to do this. How will we transform from the subjectivities shaped by our participation in the settler colonial academy? What risks are available to us so that we might better recognise the limits of our disciplinary knowledges?

These are not passing questions that merely occupied us during 2020, not simply an estrangement that can be flipped back to more comfortable norms. We now approach these questions again, in the wake of the trauma of 2020 and once again experiencing lockdown conditions between vaccination rollouts. This means an embodied memory of collective and personal distress and reflection upon its constructive effects on our intellectual and practical agility as teachers. How to sustain some of the inventiveness and intimacy which has been characteristic of this time of un-knowing? Can we keep challenging ourselves to consider deeper, more relational and less authoritative approaches to methods of teaching when the shock of the pandemic has waned? How might we share our own vulnerability with students, while maintaining safe and constructive learning?

\section{Notes}

[1] We acknowledge the work and impact of our colleagues Professor Mark McMillan and Dr Peter West in devising and leading this program.

[2] Bonny would like to express gratitude for the research, practice and dialogue of interdisciplinary colleagues Ed Hubber, Libby Porter and Rachel Wilson in shaping this course.

[3] Student quotations are reproduced with permission and approval by RMIT University in alignment with the National Statement on Ethical Conduct in Human Research.

[4] Kane refers to sound theorists Pierre Schaeffer's and Michel Chion's interests in locating the origins of acousmatic sound to the school of Pythagoras whereby "the akousmatikoi literally the 'listeners' or 'auditors' - [...] heard the philosopher lecture from behind a curtain or veil. According to Chion, Pythagoras used the veil to draw attention away from his physical appearance and toward the meaning of his discourse" (Kane, 2014, p. 5). 


\section{References}

ABC Radio National. (2012). 'Listening to Country', Awaye!

https://www.abc.net.au/radionational/programs/awaye/listening-to-country/3828920

Archer-Lean, C and SR Phillips. (2018). Decolonising the reading of Aboriginal and Torres Strait Islander writing: reflection as transformative practice. HERD, 38(1), 24-37.

Biermann, S and M Townsend-Cross. (2008). Indigenous pedagogy as a force for change. Australian journal of Indigenous education, 37, 146-154.

Biesta, G. J. J. (2016a). The beautiful risk of education. Routledge, London.

Biesta, G. J. J. (2016b). Good education in an age of measurement: ethics, politics, democracy. Routledge, London, UK.

Birch, T. (1992). 'Nothing has changed': the making and unmaking of Koori culture. https://meanjin.com.au/essays/nothing-has-changed-the-making-and-unmaking-ofkoori-culture/

Birch, T. (2017). 'Our red sands dug and sifted': sovereignty and the act of being. Sovereignty, Australian Centre for Contemporary Art, 19-26.

https://content.acca.melbourne/uploads/2017/03/Sovereignty-Catalogue.pdf

Briggs, C. (2017). Foreword. Sovereignty, Australian Centre for Contemporary Art, 4. https://content.acca.melbourne/uploads/2017/03/Sovereignty-Catalogue.pdf

Cassidy, B. (2020). Reflexive learning survey, November, RMIT University.

Cassidy, B. (2020) Structural whiteness and the business of creative writing: developing reflexive pedagogy, TEXT, 21(4). https://www.textjournal.com.au/april20/cassidy.pdf

Cole, C. (2007). How the university workshop hinders new writers from engaging with ideas. Segue online literary journal, 1-12.

https://opus.lib.uts.edu.au/bitstream/10453/3294/1/2006008734.pdf

Collis, P and J Crawford. (2017). Six groundings for Aboriginal and Torres Strait Islander story in the Australian creative writing classroom: Part 1, TEXT, 21(2). http://www.textjournal.com.au/oct17/collis_crawford.htm

Collis, P and J Crawford. (2018). Six groundings for Aboriginal and Torres Strait Islander story in the Australian creative writing classroom: Part 2, TEXT, 22(2). http://www.textjournal.com.au/oct18/collis_crawford.htm

Donnelly, D. (2012). Key issues in creative writing. Multilingual Matters, Bristol. 
Foucault, M. (1997). Technologies of the self. In P. Rabinow trans. R Hurley et al (Eds.), Ethics, subjectivity and truth, (pp, 223-251). Penguin, London,

Foucault, M. (2001). The hermeneutics of the subject. Lectures at the College de France 1981-1982, trans. G Burchell. Picador, New York.

Friere, P. (2018). Pedagogy of the oppressed, trans. M B Ramos. Bloomsbury, London.

Haroutunian-Gordon, S and M J Laverty. (2011). Listening: an exploration of philosophical traditions. Educational theory, 61(2), 117-124.

Kane, B. (2014). Sound unseen: acousmatic sound in theory and practice. Oxford University Press, Oxford.

Kwaymullina, A. (2020). Living on stolen land. Magabala Books, Broome.

Land, C. (2015). Decolonising solidarity: dilemmas and directions for supporters of Indigenous struggles. Zed Books, London.

Land, C. (2011). Decolonizing activism/deactivating colonialism. Action learning action research journal, 17(2), 42-62.

Lloyd, J. (2009). Listening across difference. Media and multiculturalism beyond the politics of coice. Continuum. Journal of media \& cultural studies, 23(4), 445 - 458.

Mahood, K. (2018). Lost and found in translation: who can talk to country? Griffith Review, $63,29-46$.

Pease, B. (2012). The politics of gendered emotions: disrupting men's emotional investment in privilege. Australian journal of social issues, 47(1), 125-42.

Red Room Company. (2017). New Shoots Victoria radio series: Episode 2. https://soundcloud.com/user-814591491/episode2

Ungunmerr-Baumann, M-R. (2002). Dadirri: inner deep listening and quiet still awareness. dadirri.org.au

Waller, L. (2018). Indigenous research methodologies and listening the Dadirri way. In T. Dreher \& A. Mondal (Eds.), Ethical responsiveness and the politics of difference (pp. 227-241). Palgrave Macmillan, Cham, Switzerland.

Worrell, T. (2018). The Aboriginal equation. Growing up Aboriginal in Australia (pp. 220222). Black Inc, Carlton. 